Very few cases of epithelioma of the thyroid gland have been put on record, the only ones with which I am familiar being cases of cylindrical cpithelioma recorded by W. Müller, Lücke, Cornil, Kaufmann, and Wölfler, and of squamous-celled epithelioma by Förster, Eppinger, Luicke, Kaufmann, and Braun. In Eppinger and Braun's cases growths in the trachea existed.

In this case no difficulty was met with in arriving at an early diagnosis, the only question being whether the tracheal tumour or the thyroid growth was the primary event. Tracheal growths coincident with thyroid malignant neoplasms are, however, very frequent, and there can be little doubt from the history of the case, and especially the early dysphagia, that the first deposit was in the thyroid gland, and that the tracheal neoplasm was secondary.

With a growth in such an advanced condition as this was when the patient first came under observation, it is usual to get not only dysphagia and dyspnœa, but pressure upon the vessels and nerves of the neck, rocal cord paralyses, fixability of the tumour by adhesions in various directions, and adhesion of the skin to the tumour, so that it cannot be moved over it. The early sign of dysphagia, which is a most valuable one in the diagnosis of these tumours, was present from the first, and this may very probably have been duc to some pressure upon the orsophagus by the portion of the right lobe, which afterwards broke down into an abscess, and this would account for the fact of no pressure upon the œsophagus being found post mortem.

The fatal termination to the case was unfortunate. But though it was felt that something must be done for the relief of the patient, it was with the full knowledge that tracheotomy in such cases is not only a very difficult operation to perform, but rarely gives relief, and in point of fact appears to have frequently terminated the patient's existence. However, it was thought better to attempt it than to let the patient die of suffocation.

\title{
THE CHLOROFORM QUESTION AND THE REPORT OF THE SECOND HYDERABAD COMMISSION.
}

THE results of the experiments of the Chloroform Commission, which has been conducted at Hyderabad by the generosity of the Nizam, and the labours of which have just been completed and given to the scientific world in a preliminary report published in the "Lancet" for January I $S$ th, 1890 , are of such vast importance that we make no excuse for recording" the conclusions liere. Quite new facts have come out from these experiments, or, rather, new confirmation of old facts and theories which were long ago broached by eminent surgeons who advocated the use of chloroform as an anesthetic suitable for all purposes. The opinion held by Syme and Simpson that chloroform when it killed did so by reason of respiratory failure, and not from cardiac paralysis, was commonly held 


\section{The Tournal of Laryngology and Rhinology.}

to be opposed to experiment and practice, as it certainly has been to the teaching of the London Schools. Surgeon-Major Lawrie, a member of both Commissions, says that he has killed scores of dogrs with chloroform, and in every case death has resulted from failure of the respiratory function; also that he has given chloroform in surgery without a death for more than twenty years, and during the last fifteen years five to ten times a day, and has never seen syncope or failure of the heart's action produced by it. It has been argued that syncope from chloroform occurs as a primary phenomenon during the initial stages of chloroform anesthesia, and that this is the form of heart failure which occurs in human beings, though not in dogs. Surgeon-Major Lawrie states that in the course of his very large experience, he has never met with a single instance of such an accident, and, if it ever does occur, it cannot be due to chloroform poisoning, though it might be caused by fright or shock. Patients have a dread of chloroform, since they are taught to believe that the anesthetic causes cardiac failure. Fainting from mere fright in the early stages of inhalation is intelligible and preventible, and syncope may be produced during the initial stages of chloroform inhalation if an operation be commenced before insensibility to possible shock is arrived at.

Surgeon-Major Lawrie contends also against any idea of "secondary syncope," which the "Lancet," representing the London School of thought, argued was produced by respiratory embarrassment as the "result of the accumulation of chloroform in the blood, leading to paralysis of the respiratory centre, and occurring late in the administration." SurgeonMajor Lawrie asserts that secondary syncope has no more real existence than primary syncope; the heart fails when the respiration ceases, and not before, and when it fails it is as a direct result of the stoppage of respiration, and as an indirect, and not direct, effect of the poisoning by chloroform. These remarks of Surgeon-Major Lawrie's were embodied in a report of a commission appointed by the Nizam of Hyderabad, in 1888 , to verify or refute the opinion that chloroform, properly administered, has no injurious or dangerous effect upon the heart. 'Two hundred experiments were performed upon dogs, and the result was arrived at that, if the respiration be carefully watched cluring the administration, it is possible to avert all risk to the heart. Indeed, so far from the danger signal arising from the condition of the heart, the contention is, that if the administration is pushed far enough to cause the heart to show signs of danger, the limits of safety have already been passed, and a fatal result must almost inevitably ensue. Of course, as Surgeon-Major Lawric states, these conclusions go directly in the teeth of those arrived at by the commissions appointed by the Royal Medical and Chirurgical Society and the British Medical Association, and the teaching of physiologists such as Snow, Claude Bernard, and McKendrick. Surgeon-Major Lawrie goes further, and states that the experiments upon which these conclusions rest are few, fallacious, and performed under conditions which invalidate their importance.

The result of this argument between the "Lancet," as representing the teaching of London, and Surgeon-Major Lawrie, as representing the teaching of Syme and Edinburgh, and the result of the first Hyderabad 


\section{The Journal of Laryngology and Rhinology.}

Commission, was the formation of a second commission, with an offer of Erooo from the Nizam's Government for the "Lancet" to send out an English representative to continue and amplify the experiments already undertaken, and thresh the subject out thoroughly whetherchloroform affects the heart or not. Dr. Lauder Brunton was chosen by the "Lancet " as the English representative, and the commission was formed as follows :-

EDWIn Lawrif, President.

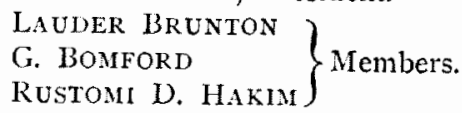

The report presented forms one of the most interesting documents published for a long time, concerning, as it does, the welfare of the thousands submitted to surgical operation.

The first series of experiments amounted to $430: 268 \mathrm{dogs}$ and $3 \mathrm{r}$ monkeys were killed outright, and $86 \mathrm{dog} s$ and 39 monkeys were submitted to artificial respiration after natural respiration had been arrested with chloroform. The animals killed had chloroform administered to them in every possible way and under every conceivable conditionfasting, after full meals, after administration of Liebig's extract, coffee, rectified spirits, ammonia, phosphorous (to induce fatty heart), morphia, strychnine, and atropine, singly or in combination. The results were uniform. Wherever chloroform was pushed the respiration stopped before the heart. The heart ceased to act in the majority of uncomplicated cases in from two to six minutes after the stoppage of respiration, and the maximum time observed was eleven minutes in a dog and twelve minutes in a monkey. The effects of chloroform do not appear to be much influenced or interfered with by the method of preparation for, or administration of, the aniesthetic, except under four conditions, viz. : in cases of very slow or prolonged administration; in cases accompanied with partial asphyxia ; in one case, where one-third of a grain of atropine was administered before the inhalation, the heart stopped very soon after the cessation of respiration; and in all cases where there was much struggling, the animals very rapidly became insensible. In these cases the interval betwcen respiratory cessation and the time of possible restoration by artificial respiration was shortened. Artificial respiration was nearly always successful if commenced within thirty seconds after cessation of the respiration, seldom successful if this period was passed, and never successful if one minute had elapsed. When morphia had been injected previously to anxesthetisation, artificial respiration was less successful in restoring respiration after its cessation. A large number of experiments were made with recording apparatus upon dogs and monkeys, and a few upon horses, goats, cats, and rabbits, in order to show the effect upon the blood pressure, heart, and respiration of inhalations of chloroform, ether, and the A. C. E. mixture, administered in various ways and under varying conditions. The results arrived at were the following :-

I. Chloroform, given continuously and freely diluted with air, causes a gradual fall in the blood pressure, provided respiration is not interfered with, and there is no struggling or involuntary holding of the breath, quiet breathing being almost invariably obtained when the aniesthetic is 


\section{The Journal of Laryngology and Rhinology.}

sufficiently diluted with air. As the blood pressure falls, the animal first becomes insensible, the respiration gradually ceases, and finally the heart. However concentrated the chloroform, it never causes sudden death from cardiac stoppage. The more diluted the chloroform the more gradual is the fall in blood pressure.

2. With interruption of the inhalation the fall of pressure continues at a rate depending upon the rapidity of the fall before the interruption, and the after-fall is probably due to absorption of a portion of the residue of chloroform in the air-passages.

3. If the chloroform administration is stopped at an early stage, pressure very soon begins to rise again to normal ; but if the chloroform is pushed, there is a period when blood pressure and respiration can no longer be restored spontaneously, although the heart goes on beating.

4. The respiration sometimes stops completely, and blood pressure rises, respiration commencing again with the rise, if the fall has been very gradual ; but, as a rule, if respiration has stopped or become slow and feeble at the time the inhalation is discontinued, and artificial respiration is not resorted to, the fall in blood pressure will continue till death follows.

5. Struggling and holding the breath disturb the gradual fall of pressure. While struggling raises it generally, it in a dog much weakened from phosphorus, fell every time it struggled. Struggling, accompanied frequently, with acceleration of the respiration and pulse, especially if the former be deep and gasping, leads to more rapid inhalation and greater after-fall. The effect of involuntarily holding the breath often causes very sudden fall, with marked slowing of the heart's action. With drawing of the breath the pressure rises, but gasping respiration succeeding, causes very rapid inhalation, with immediate sensibility and rapid fall of pressure, quickly becoming dangerous.

The combination of struggling and holding the breath and gasping (as in chloroform closely applied to the face, and without sufficient dilution), causes violent fluctuations, -speedy fall of blood pressure, dangerous depression, deep insensibility, and early stoppage of respiration, and the after-fall in these cases is rapid and prolonged.

6. Slight continuous asphyxia, as from pressure upon the neck, or hindrance of chest movements, causes irregular and exaggerated oscillations of blood pressure and slowing and irregularity of the heart's action. If accompanied with gasping respiration it increases the intake of chloroform, and causes a rapid decline of blood pressure.

7. Complete, or almost complete, asphyxia (forcibly closing mouth or nose, or tracheotomy tube) causes extremely rapid fall in blood pressure, and excessively slow cardiac action, even temporary stoppage, and the tracings resemble those produced by irritation of the cut end of the vagus. This effect of asphyxia is due to stimulation of the ragi and section of both vagi abolishes it, as does atropine (which paralyses the vagus endings).

8. Experiments in which the vagi were deliberately irritated during anæsthesia show that irritation of the vagi diminishes rather than enhances the danger of anresthetics. The slowing of the heart and 


\section{The Journal of Laryngology and Rhinology.}

circulation caused by vagus irritation (as in holding the breath in chloroform administration), retards the inhalation of chloroform and its conveyance to the nerve centres, and of itself slowing or temporary stoppage of the heart during chloroform administration is not dangerous. However, in chloroform administration, with the rise of pressure after temporary slowing of the heart and fall of pressure produced by any form of asphyxia, violent action of the heart, and efforts at respiration result, leading to rapid and dangerous inhalation of chloroform, and rapid and dangerous decline in blood pressure. It is the temporary exhaustion of the vagi after stimulation, and not the actual stimulation itself, which is to be feared. During chloroform administration neither holding the breath nor vagus inhibition can be kept up beyond a certain time, and if the chloroform be not removed from the face, one of two things must happen, viz., either great overdosing on re-establishment of respiration, or the rebounding action of the heart, causing acceleration of the circulation, the blood is quickly saturated with chloroform, and an overdose carried to the nerve centres. The commonly held theory that the danger in chloroform administration consists in slowing the heart by vagus inhibition is absolutely incorrect. It is the exhaustion of the nerve which is dangerous, not its stimulation. With a condition in which there is rapid and bounding pulse and high blood pressure, there is increased absorption of chloroform and propulsion to the medulla, more rapid paralysis of the respiratory and vasomotor centres, and precipitous fall in the pressure. Such a condition is produced in some cases by ether, division of both vagi, or a full dose of atropine. The heart already working as forcibly as possible is unable to prevent by increased work the fall in blood pressurc occurring when the vasomotor centre is paralysed. Direct action of chloroform upon the cardiac tissue is not the cause of the fall of blood pressure when it is inhaled. Indeed, if it had any effect of this kind it would become rather a source of safety than danger.

9. The effect of artificial respiration, after cessation of the natural respiration, is to cause, first, an alternate rise and fall in the blood pressure, and then a continuous rise, with final restoration of the natural respiration. In a few cases-e.g., a phosphorous dog and a horse which had an enormous overdose-artificial respiration was unsuccessful.

IO. Complete stoppage of respiration always means that an overdose has been administered, and it may have been so great as to produce prolonged inhalation after fall of blood pressure, and render restoration impossible, and it is impossible to say when the latter may not fail. A great deal depends upon the amount of the after-fall. Still, the success of artificial respiration in restoring the blood pressure is, in some cases, very remarkable, even when the heart has ceased beating, and the animal is apparently dead.

II. The dangers of too vigorous artificial respiration were instanced by rupture of the liver, and in one case the pleural cavity was found full of blood. Irritability of the heart after death was noticed in many cases, but was most marked where ether had been employed. Chloroform, when injected into the heart through the jugular vein, did not cause clotting of the blood as when ether was injected. 


\section{The Journal of Laryngology and Rhinology.}

I2. Morphine was shown to have no effect in shortening the period which may be allowed to elapse between the cessation of respiration and commencement of artificial respiration. Other drugs used had no effect upon the action of chloroform, except when their own special action became the leading feature.

13. The Committee proved by a number of experiments that shock, however induced, produced only the action due to stimulation of a sensory nerve, and nothing sugrestive of syncope or failure of the heart's action, and chloroform has, therefore, no power to increase the tendency to shock in operations, and in order to test this conclusion still further the vagi were irritated during dangerous chloroform narcosis, and it was found that the inhibition produced prevented rather than assisted the fatal effect of prolonged chloroform inhalation. The danger begins when the irritation is cliscontinued or fails any longer to inhibit the heart, and thus enable the chloroform in the lungs to be rapidly absorbed and thrown into the system, and this danger is increased by deliberately pumping the chloroform into the lungs by artificial respiration. Other experiments showed conclusively that chloroform does not increase the action of electrical stimuli applied to the vagi. The inevitable conclusion from a number of experiments (Goltz's experiments repeated on dogs, violent blows on the testicle, section of the splanchnics) is, that chloroform has no power to increase the tendency to shock or syncope during operations, and if either of these occur, it prevents rather than aggravates the danger of chloroform inhalation.

I4. Experiments upon dogs dosed with phosphorus showed that fatty heart is not affected by chloroform, and shock could not be more readily produced in these animals than in healthy ones. Chloroform in no way endangers a fatty heart, but by lowering the blood pressure lessens the work such a heart has to accomplish. Such patients die from very slight exertion or from fright.

15. The effect of hiemorrhage was tested by opening the femoral artery and allowing a considerable amount of blood to escape. Immediate lowering of the blood pressure results, which, though dangerous in itself, does not affect the action of chloroform, except that in such conditions less chloroform would be required to lead to anxsthesia, and the lowering of the pressure would prevent too rapid intake of the anæesthetic.

I6. An animal in the vertical position is not more prone to shock during various operations, and inversion of the body-head downwardsfailed to restore an animal in the last stage of chloroform poisoning.

17. Certain differences in the mamner of behaviour of different animals to chloroform are stated, but as far as its anæsthetic action goes, it is the same for all.

I8. Experiments with ether showed that efficient anesthetisation is not possible, unless some form of inhaler is used which thoroughly excludes air. If an ordinary cap, containing a sponge saturated and applied to the face very closely, the animal holding its breath and struggrling, we get immediate fall of blood pressure and slowing of the heart. If the ether is continued a condition of semi-anasthesia results, the pressure rising and falling to a slight degree. When air is rigidly 


\section{The Journal of Laryngology and Rhinology.}

excluded, pressure falls gradually as with chloroform, and with the same phenomena, anæsthesia, cessation of respiration, then of the heart, then death. It is impossible to say how far this is due to ether, and how far to asphyxia. Exactly similar effects can be brought about by making the animal inhale carbonic acid gas alone. So, if surgeons are content with semi-anæsthesia, it can be produced with perfect safety, though discomfort, by holding ether rather closely over the mouth. If perfect anesthesia is required, it must be obtained by rigid exclusion of air, and then the same dangers exist as in chloroform inhalations. The blood pressure may fall very rapidly and death ensue. Injection of ether into the jugular vin produces a fall of blood pressure and anæesthesia just as chloroform, but leads to formation of large clots in the heart, which the latter does not.

19. The A.C.E. mixture given gently, with plenty of air and usual chloroform conditions, produces the typical chloroform tracing. Given freely to a struggling animal, it can produce a very rapid and dangerous fall of blood pressure.

20. As to the accidental deaths which occurred during chloroform anasthetisation they were due to neglect in watching the respiration, or reckless administration of chloroform to prevent struggling, just as they probably occur in the human subject, and they explain those cases of supposed "sudden death" for which there is not the slightest eridence to warrant the assumption that a single one of them was due to paralysis or sudden stoppage of the heart as Snow assumes.

The behaviour of lower animals to chloroform is just the same as the human being, and the statement so frequently made that dogs are more resistant to chloroform than human beings is entirely incorrect.

Such are in the main the conclusions come to by this Commission. They have been in this report but little abridged here and there. It is seen what important results have attended these experiments, an importance which cannot be over-estimated. It is not as if the Commission drew sweeping calculations from few or imperfect experiments. The eridence upon which these conclusions are based is very extensive, and if all our preconceived ideas about chloroform are shown to be erroneous, we are bound to admit that the evidence is conclusive. It is uscless to argue as the "Lancet" does in a leading article (of January 18, IS90) that without abundant evidence the conclusions of the Commission cannot be accepted. Six hundred experiments have been made in this enquiry, and the results absolutely confirm the experiments and conclusions of the first enquiry. What more can be required? In a leader of September 2I, I890, the "Lancet" remarks :-

"Why do the results of the Nizam's Commission differ from those of European and American investigators? Is it because the experiments in India were carried on in a warmer climate? Or is it because the animals experimented upon were peculiarly resistant to the action of chloroform? These questions can only be answered by further experiments, which can hardly fail to be of practical utility, even if they afford only a partial solution of the problem; for Surgeon-Major Lawrie states in his letter, which appeared in our issue of May II, that the results of the experiments carried out by the Commission tallied exactly with his own experience. In the correspondence which occurred on the subject in the 
"Lancet," some writers agreed with Dr. Lawrie, while others supported the opposite view. We may, perhaps, fairly call these two views those of the Edinburgh and London schools. In the Scotch capital, failure of respiration is regarded as the chief or only danger; while in the metropolis, failure of the heart is more feared. It is quite possible that the surgeons in both cities are right, and that the habits or mode of living of the people may lead to differences in the resisting power of the cardiac or respiratory apparatus respectively. The proportion of gouty patients is much larger in London than in Edinburgh, and when we consider that the natives of India appear to resemble the Scotch in their comparative immunity from cardiac paralysis by chloroform, it will be advisable for the Commission to ascertain, if possible, what the conditions are which enable the heart either in (logs or men to resist the power of chloroform, or which lead to its stoppage during the administration of the drug. It may not be possible to work out completely all the questions which may arise, but if the Hyderabad Commission, with the aid of Dr. Lauder Brunton, can settle definitely the question whether chlorofurm does or does not affect the heart directly, a most important practical object will have been attained by means of the Nizam's generous offer."

One might grant the possibility that there is a striking difference in the constitution of a European and an Indian, but it is surely refining criticism to sugyest that there should be such a difference between the man of Edinburish and the man of London as to make the former less liable to cardiac paralysis from chloroform than the latter. That cither the natives of India or the citizens of Edinburgh are any less liable to cardiac paralysis than the citizens of London we do not believe. While in London all teaching has been to insist upon attention being paid alone to the heart during chloroform administration, in Edinburgh, and with those who, like Surgeon-Major Lawrie, have imbibed the teaching of this school, attention has been paid primarily to the respiration as a danger signal. Consequently, those who have followed the latter as a guiding principle have had a much more favourable record of experience than those who, by relying upon cardiac signs have allowed the farourable moment for recovery to pass by: It is this which makes the apparent difference between the results of chloroform anesthetisation in Edinburgh, and India, and I.ondon, and not, in all reasonable probability, any difference in climate. It must be remembered that the results arrived at experimentally by these two commissions endorse the conclusions arrived at long ago from clinical observation by the Edinburgh teachers. Until some investigation upon the same scale, conducted in London or America, can show the conclusions arrived at by the Hyderabad Commission to be erroneous, there seems to be no course open but to accept these conclusions fully.

The report of this Commission concludes with some practical considerations, which we will append in the commissioners' own words :-

\section{I'R.ICTICAI CONCIUSIONS.}

The following are the practical conclusions which the Commission think may fairly be decluced from the experiments recorded in this report :--

I. The recumbent position on the lack and absolute freedom of respiration are essential. 


\section{The Journal of Laryngology and Rhinology.}

II. If during an operation the recumbent position on the back cannot, from any cause, be maintained during chloroform administration, the utmost attention to the respiration is necessary to prevent asphyxia or an overdose. If there is any doubt whatever about the state of respiration, the patient should be at once restored to the recumbent position on the back.

III. To ensure absolute freedom of respiration, tight clothing of every kind, either on the neck, chest, or abdomen, is to be strictly aroided; and no assistants or bystanders should be allowed to excrt pressure on any part of the patient's thorax or abdomen, even though the patient be struggling violently. If struggling cloes occur, it is alway's possible to hold the patient down by pressure on the shoulders, pelvis, or legs without doing anything which can by any possibility interfere with the free movements of respiration.

IV. An apparatus is not essential, and ought not to be uscl, as, being made to fit the face, it must tend to produce a ccrtain amount of a iphyxia. Moreover, it is apt to take up part of the attention which is recuired elsewhere. In short, no matter how it is made, it introduces an element of danger into the administration. $\Lambda$ convenient form of inhaler is an open cone or cap with a little absorbent cotton inside at the apex,

$V$. At the commencement of inhalation care should be taken, by not holding the cap too close over the mouth and nose, to avoid exciting, struggling, or holding the breath. If struggyling or holding the breath do occur, great care is necessary to avoid an over-dose (luring the dec] inspirations which follow. When quiet breathing is ensured as the patient begins to go over, there is no reason why the inhaler should not be applied close to the face; and all that is then necessary is to watch the cornca and to see that the respiration is not interfered $w$ ith.

VI. In children, crying ensures free admission of chloroform into the lungs; but as struggling and holding the breath can hardly be avoided, and one or two whiffs of chloroform may be sufficient to produce complete insensibility, they should always be allowed to inhale a little fresh air during the first deep inspirations which follow. In any struggling persons, but especially in children, it is essential to remove the inhaler after the first or second deep inspiration, as enough chloroform may have becn inhaled to produce deep anæsthesia, and this may only appear, or may decpen, after the chloroform is stopped (vide supra). Struggling is best avoided in adults by making them blow out hard after each inspiration during the inhalation.

VII. The patient is, as a rule, anxesthetised and ready for the operation to be commenced when unconscious winking is no longer produced by touching the surface of the eye with the tip of the finger. 'The anasthetic should never under any circumstances be pushed till the respiration stops ; but when once the cornea is insensitive, the patient should be kept gently under by occasional inhalations, and not be allowed to come out and renew the stage of struggling and resistance.

VIII. As a rule, no operation should be commenecel until the patient is fully under the influence of the anasthetic, so as to aroid all chance of death from surgical shock or fright. 


\section{The Journal of Laryngology and Rhinology.}

IX. The administrator should be guided as to the effect entirely by the respiration. His only object, while producing anæesthesia, is to see that the respiration is not interfered with.

$\mathrm{X}$. If possible, the paticnt's chest and abdomen should be cxposed during chloroform inhalation, so that the respiratory movements can be seen by the administrator. If anything interferes with the respiration in any way, however slightly, even if this occurs at the very commencement of the administration, if breath is held, or if there is stertor, the inhalation should be stopped until the breathing is natural again. This may sometimes create delay and inconvenience with inexperienced administrators, but experience will make any administrator so familiar with the respiratory functions under chloroform that he will in a short time know almost by intuition whether anything is going wrong, and be able to put it right without delay before any langer arises.

XI. If the breathing becomes embarrassed, the lower jaw should be pulled, or pushed from behind the angles, forward, so that the lower teeth protrude in front of the upper. This raises the epiglottis and frees the larynx. At the same time it is well to assist the respiration artificially until the embarrassment passes off.

XII. If by any accident the respiration stops, artificial respiration should be commenced at once, while an assistant lowers the head and draws forward the tongue with catch-forceps, by Howard's method, assisted by compression and relaxation of the thoracic walls. Artificial respiration should be continued until there is no doubt whatever that natural respiration is completcly re-cstablished.

XIII. A small dose of morphia may be injected subcutaneously before chloroform inhalation, as it helps to kecp the patient in a state of anesthesia in prolonged operations. There is nothing to snow that atropine does any good in connection with the administration of chloroform, and it may do a very great deal of harm.

XIV. Alcohol may be giren with advantage before operations under chloroform, provided it does not cause excitement, and merely has the effect of giving a patient confidence and steadying the circulation.

The Commission has no doubt whaterer that, if the above rules be followed, chloroform may be given in any case requiring an operation with perfect ease and absolute safety, so as to do good without the risk of eril.

EDWARD LAWRIE (President),

T. LAUDER BRENTON,

$\left.\begin{array}{l}\text { G. BOMFORI, } \\ \text { RUSTOMJI D. HAKIM, }\end{array}\right\}$ Members.

EDWARD LAWRIE, Surgeon-Major.

Iyderabad, December 18, I889. 